\title{
Contribuições de um núcleo específico de educação física em um curso de educação na cultura digital para a prática pedagógica na visão de professores-cursistas
}

\section{Contributions of a specific physical education core in an education course in the digital culture for the pedagogical practice in the view of teachers-cursists}

\section{Contribuciones de un núcleo de educación física específico en un curso de educación en la cultura digital para la práctica pedagógica en la visión de profesores-cursistas}

\author{
iD) Juliano Silveira \\ Universidade Federal de Santa Catarina, Florianópolis, Santa Catarina, Brasil \\ Juliano_silveira@yahoo.com.br \\ iD Giovani De Lorenzi Pires \\ Universidade Federal de Santa Catarina, Florianópolis, Santa Catarina, Brasil \\ delorenzi57@gmail.com
}

Resumo: Este artigo objetiva refletir sobre as percepções de professores de Educação Física acerca das contribuições de um núcleo de estudos, oferecido no âmbito de uma especialização em educação na cultura digital, para a sua prática pedagógica. Os dados produzidos para este estudo de caso de caráter qualitativo são oriundos de entrevistas semiestruturadas realizadas com 10 professores/cursistas. Para análise dos dados foi utilizada a análise de conteúdo. Os resultados versam sobre uma melhor compreensão acerca de como utilizar as tecnologias, aquisição de maior segurança para planejar, maior entendimento sobre 
Contribuições de um núcleo específico de educação física em um curso de educação... Juliano Silveira • Giovani De Lorenzi Pires

as relações entre Educação Física e cultura digital, além das possibilidades de trabalho coletivo nas escolas, o que reforça a importância de se investir na formação continuada.

Palavras-chave: Educação Física. Formação de Professores. Cultura Digital

Abstract: This article aims to reflect on the perceptions of Physical Education teachers about the contributions of a study core, offered within the scope of a specialization in education in digital culture, for their pedagogical practice. The data produced for this qualitative case study come from semi-structured interviews conducted with 10 teachers / course participants. For data analysis, content analysis was used. The results are about a better understanding of how to use technologies, acquisition of greater security for planning, greater understanding of the relationships between Physical Education and digital culture, in addition to the possibilities of collective work in schools; which reinforces the importance of investing in continuing education.

Keywords: Physical Education. Teacher training. Digital Culture

Resumen: Este artículo tiene como objetivo reflexionar sobre las percepciones de los docentes de Educación Física so bre las contribuciones de un grupo de estudio, ofrecido dentro del alcance de una especialización en educación en cultura digital, para su práctica pedagógica. Los datos producidos para este estudio de caso cualitativo provienen de entrevistas semiestructuradas realizadas con 10 profesores / participantes del curso. Para el análisis de datos, se utilizó el análisis de contenido. Los resultados son sobre una mejor comprensión de cómo utilizar las tecnologías, la adquisición de una mayor seguridad para la planificación, una mayor comprensión de las relaciones entre la educación física y la cultura digital, además de las posibilidades de trabajo colectivo en las escuelas; lo que refuerza la importancia de invertir en educación continua.

Palabras clave: educación física. Formación de professores. Cultura digital

Submetido em: 10-07-2020

Aceito em: 05-11-2020 
Contribuições de um núcleo específico de educação física em um curso de educação... Juliano Silveira • Giovani De Lorenzi Pires

\section{Introdução}

É possível afirmar que o cenário contemporâneo tem sido marcado por uma dinâmica cultural em que as tecnologias digitais de informação e comunicação (TDIC) adquirem lugar de destaque, alterando significativamente nossas práticas cotidianas nas mais diferentes esferas (RUDIGER, 2011). Trata-se de um "processo crescente de reorganização das relações sociais mediadas pelas tecnologias digitais, afetando em maior ou menor escala todos os aspectos da ação humana" (PRETTO; ASSIS, 2008, p. 78), caracterizando o nosso ingresso em uma cultura digital (RAMOS et al, 2013).

Em face a essa mudança cultural, a própria educação escolar se vê pressionada a se reinventar em relação às suas didáticas, mas também no que tange ao currículo, sobretudo ao considerar-se uma nova forma de organização, produção e acesso ao conhecimento potencializado pelas TDIC. E soma-se a isso o papel que esses meios tecnológicos assumem nas vivências cotidianas das crianças e jovens que frequentam nossas instituições escolares (BUCKINGHAM, 2012).

No que tange especificamente à Educação Física escolar, pode-se afirmar que atualmente as representações sociais inerentes às práticas corporais pelas quais esse componente curricular é responsável são, em grande parte, produzidas e compartilhadas por meio das TDIC. Daí a necessidade de se proporcionar aos alunos a tematização de suas linguagens com o aporte das TDIC como complemento das aprendizagens possíveis sobre/com práticas corporais no âmbito da cultura digital (PIRES; LAZAROTTI FILHO; LISBOA, 2012).

Não é por outro motivo que as diretrizes nacionais para a formação de professores passaram por mudanças a fim de contemplar as questões referentes às tecnologias e à cultura digital (BIANCHI, 2014), abarcando assim as licenciaturas, mas também 
Contribuições de um núcleo específico de educação física em um curso de educação... Juliano Silveira • Giovani De Lorenzi Pires

dando indicativos relevantes a serem incluídos no âmbito da formação continuada. E, nesse sentido, uma importante iniciativa desenvolvida na esfera da formação continuada foi a criação e oferta do curso de especialização Educação na Cultura Digital. ${ }^{1}$

Esse curso, de caráter multidisciplinar, foi composto por uma série de núcleos de estudos que contemplavam as especificidades didático-pedagógicas dos diferentes componentes curriculares. Dentre esses núcleos, foi oferecido o Núcleo Específico de Educação Física e TDIC (NEEF), sendo que sua produção e oferta ficou a cargo do LaboMídia/UFSC (PIRES et al, 2017). Esta especialização foi oferecida na modalidade de ensino a distância, em caráter piloto, pelo Departamento de Metodologia de Ensino (MEN) do Centro de Ciências da Educação da Universidade Federal de Santa Catarina e foi destinado a professores de escolas públicas de Santa Catarina entre os anos de 2014 e 2016.

Levando em consideração a importância das propostas formativas desenvolvidas ao longo do Núcleo Específico Educação Física e TDIC, assim como o caráter recente que as suas temáticas assumiam para os professores participantes do citado núcleo, acreditamos ser necessário investigar as repercussões dessa formação na prática pedagógica dos docentes. Dessa maneira, o objetivo do presente artigo é refletir sobre as percepções de professores de Educação Física acerca das contribuições do Núcleo Específico Educação Física e TDIC para a sua prática pedagógica cotidiana.

\section{Metodologia²}

Este artigo pode ser caracterizado como decorrente de um estudo de caso, com abordagem qualitativa, que assume como objeto a oferta-piloto de um núcleo de estudos no âmbito do curso de especialização em educação na cultura digital. Para Minayo (2012, p. 37), "a abordagem qualitativa aprofunda-se no mundo dos sig-

\footnotetext{
1 Para mais informações sobre o curso, acessar: http://educacaonaculturadigital.mec.gov.br.

20 projeto de pesquisa foi submetido à avaliação do Comitê de Ética em Pesquisa com Seres Humanos (CEPSH) da Universidade Federal de Santa Catarina (UFSC) e aprovado sem restrições, com o número 57911816.9.0000.0121.
} 
Contribuições de um núcleo específico de educação física em um curso de educação... Juliano Silveira • Giovani De Lorenzi Pires

nificados das ações e relações humanas, um lado não perceptível e não captável em equações, médias e estatísticas", permitindo, assim, explorar a complexidade das questões referentes ao tema investigado.

Epistemologicamente, propõe-se uma aproximação com os fundamentos da abordagem sócio-histórica, que consiste "numa preocupação de compreender os eventos investigados, descrevendo-os e procurando as suas possíveis relações, integrando o individual com o social" (FREITAS, 2007, p. 28). Essa abordagem possui um caráter dialógico e considera a interação como fundamental no estudo dos fenômenos humanos, tendo em vista que os dados produzidos decorrem das relações que o pesquisador estabelece com os sujeitos investigados.

Para a produção dos dados da pesquisa que servem de base para este artigo, foram realizadas entrevistas de caráter semiestruturado. A opção por essa técnica se deve ao fato de permitir ao pesquisador maior flexibilidade na articulação do diálogo com os entrevistados, contemplando informações ligadas ao objeto de estudo que possam não estar previstas no roteiro de entrevista.

Em relação aos sujeitos participantes da pesquisa, trata-se de 10 professores e professoras de Educação Física/cursistas do Núcleo Específico que participaram de todas as etapas do curso de especialização. ${ }^{3}$ Vale salientar que os professores participantes da pesquisa eram procedentes de diferentes regiões de Santa Catarina, por isso as entrevistas foram realizadas predominantemente a distância, via Skype, gravadas e transcritas para posterior análise.

Por último, no que tange à ferramenta metodológica adotada para a interpretação dos dados produzidos em campo, optou-se pela análise de conteúdo. Sua função é a interpretação, ou atribuição de significados às características captadas nos dados produzidos em campo, na perspectiva de se descobrir o que está por trás

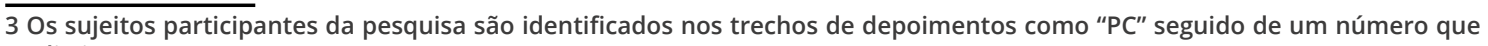
os distingue. 
Contribuições de um núcleo específico de educação física em um curso de educação... Juliano Silveira • Giovani De Lorenzi Pires

dos conteúdos manifestos, indo além das aparências do que está sendo comunicado (BARDIN, 2009).

No processo de exploração dos materiais selecionados para a análise foram estabelecidas categorias a partir da incidência de palavras-chave recorrentes que se constituíram em unidades de registro (BARDIN, 2009). Dentre as categorias estabelecidas, obteve destaque "as repercussões do Núcleo Específico Educação Física e TDIC na prática pedagógica", que abarcou, dentre outros elementos, as ações desenvolvidas pelos professores/cursistas com base na experiência do núcleo. Tais elementos são contemplados nas discussões do presente artigo.

\section{Resultados e discussão}

Ao considerarmos a categoria de análise que versou sobre as repercussões do Núcleo Específico Educação Física e TDIC na prática pedagógica, foram destacados para a presente discussão aspectos relacionados com o crescimento pessoal e enriquecimento das aulas, mudanças no modo de pensar as TDIC na escola e nas aulas de Educação Física, novas formas de planejar, o subsídio às ações pedagógicas coerentes com a contemporaneidade e a valorização de propostas coletivas no cotidiano escolar.

No que tange às percepções sobre o crescimento pessoal e enriquecimento das aulas, o professor/cursista 2, PC2, afirma que:

Eu aprendi muito com o núcleo, foi muito bom ter feito [...]. Hoje eu tenho uma noção, assim, bem maior e uso bem mais as tecnologias na minha prática pedagógica. Quando eu vejo que tenho uma possibilidade boa para usar, eu tô utilizando. (PC2, em entrevista aos autores, setembro 2016).

Essa possível ampliação do conhecimento sobre como utilizar as TDIC na escola parece demonstrar o quanto as relações entre 
Contribuições de um núcleo específico de educação física em um curso de educação... Juliano Silveira • Giovani De Lorenzi Pires

educação e tecnologia ainda precisam ser aprofundadas, no sentido de se apresentar aos docentes formas de apropriação didático-pedagógica dessas ferramentas, assim como propor o esclarecimento sobre a própria mudança nos processos de ensino que esses meios tendem a representar. De fato, hoje em dia, a escola "procura dar respostas a tal fenômeno, adequando-se no que tange à incorporação das tecnologias ao contexto escolar, mas com dificuldades em relação aos modos de tratar os conteúdos e as metodologias, na interação com as TDIC" (SILVEIRA; PIRES, 2016, p. 93-94). E acrescenta-se que, com a experiência do Núcleo, o professor/cursista percebe que passou a ver mais possibilidades de como trabalhar com as TDIC em suas aulas, compreendendo meIhor a necessidade de se proporcionar "sólidas bases teórico-metodológicas para que a mídia e as novas tecnologias digitais sejam apropriadas e ressignificadas na sua interface com os conteúdos da Educação Física" (PIRES; LAZZAROTTI FILHO; LISBOA, 2012, p. 74).

Já o professor/cursista 10, PC10, relatou as seguintes contribuições do Núcleo para o seu crescimento profissional:

\footnotetext{
Eu não sabia que eu era capaz de fazer tanta coisa, né?! [...] eu não tinha noção de quanto isso ia enriquecer as minhas aulas e mudar completamente a forma de ensinar. E os recursos favoreceram a autonomia dos alunos, foi o que mais me encantou em colocar os recursos na sala de aula, nas minhas aulas. (PC10, em entrevista aos autores, outubro 2016).
}

O docente relata que o Núcleo contribuiu para a qualidade das suas aulas, especialmente pelas possibilidades abertas pela utilização das TDIC no que diz respeito à valorização da autonomia dos alunos durante as práticas pedagógicas. Assim, é preciso considerar que as novas tecnologias carregam consigo implicações sobre as formas como acessamos as informações e também como produzimos os conhecimentos atualmente, resultando em uma nova compreensão de aluno, não somente como aquele que não 
Contribuições de um núcleo específico de educação física em um curso de educação... Juliano Silveira • Giovani De Lorenzi Pires

conhece e que estabelece uma relação heterônoma com o professor, mas como alguém exposto a possibilidades de aprendizado, informações, saberes, de forma conectada (BARTOLOMÉ, 2011). A própria redescoberta como professor, ao dizer que não sabia que era capaz de fazer tantas coisas, é um indicativo de como uma perspectiva de formação docente pautada na apropriação das TDIC na prática pedagógica pode contribuir para a ressignificação de suas aulas.

Um segundo conjunto de percepções sobre as contribuições do Núcleo para a prática pedagógica versa sobre mudanças no modo de pensar sobre as relações entre TDIC e escola. Nesse sentido, o professor/cursista 3, PC3, afirma que:

Hoje, com certeza eu penso diferente. Tenho mais conhecimento e segurança no uso das TDICs em sala de aula. Posso dizer que as leituras e trocas de experiências com colegas e tutores colaboraram também para provocar a mudança em minha ação pedagógica diária, encontrar novas estratégias para pôr em prática diferentes formas de utilizar e introduzir as TDICs nas aulas de Educação Física. (PC3, em entrevista aos autores, novembro 2016).

Percebe-se que a participação no núcleo permitiu a aquisição de conhecimentos sobre as TDIC, resultando em maior segurança por parte do docente para o desenvolvimento de ações com as tecnologias em suas aulas. De fato, o medo de não saber utilizar as tecnologias ou de saber menos do que os alunos parece ser um fator limitador para a integração das TDIC às aulas e, assim, o domínio instrumental desses meios e a reflexão sobre formas de utilizá-los em sala representa um aspecto importante na superação de tais receios. Conforme Souza Neto (2015, p. 332), “o medo de mostrarem que há coisas que não sabem fazer ou conhecimentos que não dominam [...] acabam funcionando como barreiras paralisantes de qualquer relacionamento pedagógico com as TDIC".

Essa mudança de compreensão sobre as TDIC também é enfatizada pelo professor/cursista 4, PC4: 
Contribuições de um núcleo específico de educação física em um curso de educação... Juliano Silveira • Giovani De Lorenzi Pires

Bom, na verdade eu nunca tinha pensado em trabalhar realmente, inserir as tecnologias assim. E, conforme o núcleo foi pedindo...então assim, a gente viu como desenvolver as atividades e viu também que não é um bicho de sete cabeças[...]. Eu acho que é um recurso muito válido, acho que auxilia na avaliação e também nas aulas mesmo, tornando-as mais atrativas. (PC4, em entrevista aos autores, outubro 2016).

É interessante notar a compreensão a priori do docente sobre as impossibilidades de se inserir as tecnologias nas aulas de Educação Física, possivelmente ligada a uma formação inicial que ainda pouco considera esse tipo de abordagem na relação entre Educação Física, mídias e tecnologias, conforme aponta o estudo de Silveira, Brüggemann e Bianchi (2019). O docente também relata que, conforme as atividades eram realizadas, sua percepção inicial de que um trato pedagógico com as TDIC nas aulas de Educação Física seria algo difícil de realizar acabou sendo relativizada - justificando as apostas na formação continuada. E ressalta, ao final do trecho destacado de seu depoimento, a percepção de que aliar as TDIC às suas aulas se constituiria em um fator positivo por torná-las mais atrativas. Assim, a aproximação pretendida constituir-se-ia numa espécie de chamariz para os alunos que se sentiriam atraídos pelas TDIC, fazendo com que as aulas ficassem mais dinâmicas. Vê-se, portanto, a compreensão de que as TDIC servem "mais como recurso de exposição de conteúdos, como também para entreter e/ou motivar os alunos como recurso de atenção e concentração pedagógicas, [...] servindo mais como inovação didática e muito menos como inovação curricular" (SOUZA NETO, 2015, p. 6).

Um terceiro aspecto referente às contribuições do núcleo versa sobre as novas perspectivas abertas em termos de planejamento, novas atividades e o embasamento teórico das ações mediadas por tecnologias na escola. De acordo com o professor/cursista 1, PC1: 
Contribuições de um núcleo específico de educação física em um curso de educação... Juliano Silveira • Giovani De Lorenzi Pires

Então, hoje tenho uma visão melhor sobre isso. E até para planejar as aulas já mudou. Fazer uma pesquisa, fazer algum outro esporte, trabalhar o atletismo [...]. Hoje eu não tenho dificuldade para isso. Tirando os limites que cada escola tem, não teria dificuldade em montar um planejamento integrando as TDICS. (PC1, em entrevista aos autores, setembro 2016).

O professor/cursista apresenta uma percepção de que, após o NEEF, sua própria dinâmica de planejamento das aulas se modificou, passando a ver possibilidades de integração das TDIC que antes julgava impossível. Esse aparente reflexo do Núcleo na ação docente, que diz respeito à utilização das TDIC nos processos de planejamento das aulas tende a ser significativo uma vez que, embora não estejam implícitas dimensões críticas e criativas na abordagem com as TDIC, parece revelar uma "instrumentalização ao uso pedagógico" (SOUZA NETO, 2015). Dessa forma, a apropriação inicial das tecnologias, mesmo que instrumentalmente, carrega consigo potencialidades para a abordagem das demais dimensões, cabendo ao docente decidir em quais momentos poderá valer-se delas no trato com os conhecimentos pelos quais seu componente curricular é responsável.

Sobre a questão do embasamento teórico das ações a serem desenvolvidas com as TDIC nas escolas, temos os seguintes depoimentos:

Hoje, pra mim, eu tenho um pouquinho mais de embasamento teórico e prático dentro das minhas aulas graças a esse núcleo, porque antes não sabia fazer uma atividade usando a tecnologia. Então, pra mim foi excepcional o núcleo, me ajuda bastante hoje dentro da escola, na minha prática pedagógica. (PC8, em entrevista aos autores, outubro 2016).

Eu acho assim que o núcleo só veio mostrar que realmente isso [utilizar as TDIC] é possível e daí, ainda mais fundamentado. Daí você tem a teoria e a prática e com certeza é uma forma de sacudir as nossas aulas [...] e essa nova perspectiva que o núcleo 
Contribuições de um núcleo específico de educação física em um curso de educação... Juliano Silveira • Giovani De Lorenzi Pires

mostra pra gente realmente leva a gente a inovar as nossas aulas, a nossa prática. (PC10, em entrevista aos autores, outubro 2016).

Face ao exposto, vê-se que o NEEF proporcionou um maior embasamento teórico acerca de abordagens com as tecnologias e auxiliou no aprendizado sobre como se apropriar das TDIC nas aulas de Educação Física, tendo reflexos sobre a abordagem dos conteúdos em suas aulas na escola. Isto porque as articulações entre Educação Física e TDIC, especialmente no âmbito da mídia-educação, que envolveriam a promoção de experiências de ensino-aprendizagem com base em suas três dimensões, impõem ao professor a tarefa de "desenvolver projetos de ensino que priorizem o diálogo entre movimento e as TDICs" (PIRES et al., 2017, p. 38). Assim, considerando a carência de tematizações acerca da mídia-educação (física) nos currículos de formação inicial nessa área, parece justificável a percepção docente de que a tematização no âmbito da formação continuada tenha possibilitado uma compreensão fundamentada de tais articulações nas aulas do seu componente curricular.

Outro conjunto de percepções sobre as contribuições do núcleo dizem respeito a uma compreensão diferente do trato com os conhecimentos nas aulas de Educação Física a partir da integração das TDIC. Dessa maneira, para o professor/cursista 3, PC3:

Integrar as TDICs às aulas de Educação Física é desafiador e necessário. A gente vê que os alunos estão se apropriando com mais frequência das ferramentas digitais. É algo que já tá na vida deles. E essa integração tem que ser realizada de forma natural para atribuir conhecimentos para além dos conteúdos formais, pois hoje, a gente tem uma cultura que entrelaça o digital às práticas corporais. Está presente no lazer, nos jogos, brincadeiras... E nós temos que entender que as TDICs podem ser um instrumento mediador nas ações pedagógicas para que a gente possibilite a formação crítica e criativa dos alunos. (PC3, em entrevista aos autores, novembro 2016). 
Contribuições de um núcleo específico de educação física em um curso de educação... Juliano Silveira • Giovani De Lorenzi Pires

O professor/cursista 3 afirma que as práticas corporais, que fazem parte do objeto de intervenção da Educação Física, são apresentadas aos alunos por meio das mídias/tecnologias e, portanto, caberia ao professor a proposição de mediações pautadas em uma abordagem crítica acerca desses processos. Ressalta-se assim mais uma vez a importância da formação inicial e continuada em Educação Física "proporcionar o acesso e a apropriação de fundamentos conceituais e metodológicos que permitam tematizar e recriar significados a respeito da cultura de movimento, incorporando as TDIC no trabalho pedagógico, além da problematização do discurso midiático-esportivo" (PIRES et al., 2017, p. 128). E é interessante notar a presença de elementos ligados à mídia-educação no trecho destacado no depoimento, revelando o nível de apropriação conceitual do docente acerca dos conteúdos que fizeram parte do núcleo específico de Educação Física.

Ainda na presente perspectiva, o professor/cursista 9, PC9, contribui para este debate, enfatizando uma TDIC específica:

No caso do videogame, seria muito legal trabalhar isso com os alunos, ia dar um up pra eles quererem vir para a escola. Não... hoje tem aula de educação física...não vou jogar lá no sol, ahhh... hoje a aula é lá...vai ser futebol...nós vamos aprender como é a vida de um técnico...então, eu acho que tá precisando de inovação nas aulas [...] Esse núcleo acabou me abrindo os horizontes com essa questão das mídias. (PC9, em entrevista aos autores, setembro 2016).

O docente compreende que as TDIC podem representar uma inovação das aulas por proporcionar uma nova forma de se relacionar com o conhecimento, tornando as aulas mais atrativas para os alunos. Aqui é importante salientar que, por mais importante que a dimensão instrumental seja, não se trataria apenas da mera inclusão dos meios tecnológicos, como mais uma ferramenta a disposição do educador, mas possibilitaria uma mudança de atitude por parte do docente na abordagem do conhecimento, envolvendo a construção de alternativas pedagógicas que propiciem aos 
Contribuições de um núcleo específico de educação física em um curso de educação... Juliano Silveira • Giovani De Lorenzi Pires

alunos a participação e construção do conhecimento para além de uma aula tradicional, eletronicamente mediada. Conforme Pretto e Assis (2008, p. 80), “No campo da educação, formulamos a ideia de que a incorporação dessas tecnologias não pode se dar meramente como ferramentas adicionais, complementares, como meras animadoras dos tradicionais processos de ensinar e de aprender". Por isso o videogame é apontado sim como um atrativo, mas, sobretudo como motivador para a abordagem de outros aspectos ligados ao conteúdo futebol, por exemplo, para além daqueles vivenciados nas quadras ou ginásios.

Também foram destacados pelos professores/cursistas alguns elementos sobre o papel cumprido pelo Núcleo de subsidiar uma ação pedagógica coerente com a dinâmica cultural contemporânea. Nessa perspectiva, o professor/cursista 3, PC3, afirma que:

[...] a necessidade de conhecimento da geração atual é outra. As tecnologias estão presentes no nosso cotidiano, influenciando nossos hábitos, comportamentos, relacionamentos, modificando nossa forma de agir e de pensar. Penso que, nós professores, devemos assumir o papel de mediador na elaboração crítica e criativa dos alunos, para que eles sejam capazes de selecionar as informações significativas, e transformá-las em novos conhecimentos. (PC3, em entrevista aos autores, novembro 2016).

O entrevistado compreende que problematizar as tecnologias no cotidiano pedagógico é uma ação necessária, tendo em vista, especialmente, as demandas cognitivas das novas gerações, que têm boa parte das atividades de seu cotidiano mediadas pelas TDIC, ou seja, já nasceram nesse contexto. De acordo com Buckingham (2010, p. 38), "A mídia digital - Internet, telefonia móvel, jogos de computador, televisão interativa - hoje é um aspecto indispensável no tempo de lazer das crianças e dos jovens". E, assim sendo, ressalta-se a importância da mídia-educação considerando essa onipresença das tecnologias na vida das crianças e jovens, constituindo-se em verdadeiros alicerces da cultura contemporânea "como meios potenciais de participação ativa do ci- 
Contribuições de um núcleo específico de educação física em um curso de educação... Juliano Silveira • Giovani De Lorenzi Pires

dadão e como ferramentas de expressão da criatividade pessoal" (BEVORT; BELLONI, 2009, p. 1099).

Também na esfera de uma educação conectada com as demandas formativas das novas gerações, o professor/cursista 5 , PC5, salienta que:

As tecnologias digitais, elas vieram, vão ficar, porque realmente elas melhoram a vida da gente em todos os sentidos. Não tem como negá-las, já estão dentro das escolas, porque os alunos já estão inseridos neste processo digital, faz parte da vida deles. (PC5, em entrevista aos autores, outubro 2016).

O professor/cursista 5 relata então que as tecnologias estão presentes no cotidiano dos alunos e que, portanto, a integração das TDIC às práticas pedagógicas desenvolvidas na escola é uma necessidade, principalmente levando em consideração que "os jovens, adolescentes e crianças do século XXI interagem de forma frenética nas redes suportadas pela Internet, que estruturam os seus modos de aceder à informação, estabelecer relações, pensar, agir, aprender e comunicar" (ALMEIDA, 2012, p. 9). Tal integração necessária envolveria, nessa perspectiva, a reivindicação por melhores condições das escolas em termos de infraestrutura e investimentos em tecnologias e formação docente (QUARTIERO; BONILLA; FANTIN, 2012).

Essa ação de integrar as tecnologias à prática pedagógica em resposta a uma demanda educacional das novas gerações, em alguns casos, resultou em avaliações positivas por parte dos alunos nas escolas, como destacado nos seguintes trechos de depoimentos:

No ano passado a gente teve que optar por uma turma, então as turmas que vem agora e tal, eles perguntam: professor, a gente vai fazer trabalho como o professor fez no ano passado? (PC4, em entrevista aos autores, outubro 2016). 
Contribuições de um núcleo específico de educação física em um curso de educação... Juliano Silveira • Giovani De Lorenzi Pires

\begin{abstract}
E os alunos também percebem isso [a mudança na metodologia das aulas]. No segundo bimestre, no conselho de classe, tem aquelas folhas dos alunos, que é dada para eles preencherem... enfim, e ali, uma das disciplinas que eles botaram que gostaram da prática pedagógica, da metodologia utilizada pelos professores, foi a educação física. (PC2, em entrevista aos autores, setembro 2016).
\end{abstract}

No primeiro caso é destacado que os alunos avaliaram positivamente as experiências desenvolvidas com base nas atividades previstas no NEEF, questionando o docente sobre a presença de trabalhos na mesma perspectiva em seu planejamento para o ano letivo. Já no segundo depoimento, o docente afirma que as atividades desenvolvidas com as TDIC em suas aulas, durante e após o Núcleo, foram positivamente avaliadas pelos alunos, como um diferencial em termos de metodologia de trabalho nas aulas de Educação Física. Pode-se afirmar que essa avaliação positiva está ligada ao fato de que as crianças e jovens participam cotidianamente de uma cultura midiática que marca seus modos de comunicação, acesso e também produção de conteúdos nas dinâmicas proporcionadas pela internet (BUCKINGHAM, 2010).

A adoção de práticas com as TDIC nas aulas, mesmo que de forma apenas instrumental, numa perspectiva determinista de inovação didática, parece representar uma aproximação com as citadas dinâmicas inerentes à cultura digital, sendo então bem recebidas pelos alunos. Contudo, a ação docente precisa ir além, reconhecendo que as vivências com as TDIC muitas vezes são permeadas por uma lógica comercial, com ideologias e interesses próprios, que precisam ser compreendidos pelos alunos; e, dessa maneira, seria importante, para além da inclusão das TDIC como ferramentas didáticas, proporcionar uma formação que permitisse aos alunos interrogarem-se criticamente sobre essas tecnologias e sua onipresença em suas vidas.

Por fim, dentre as contribuições do NEEF, também podem ser destacados alguns elementos sobre a importância da proposta 
Contribuições de um núcleo específico de educação física em um curso de educação... Juliano Silveira • Giovani De Lorenzi Pires

formativa vivenciada pelos professores/cursistas na perspectiva de uma valorização do coletivo escolar. Dessa maneira, segundo o professor/cursista 6, PC6:

[...] O pessoal [na escola] fala: essas coisas que vocês não sabiam e agora sabem...podem nos ajudar. [...] Eu acho que essa pós-graduação foi sim de um grande valor para conhecimento nosso e enriquecimento do grupo enquanto a gente trabalhar no coletivo. Porque a gente acaba às vezes se isolando muito e esquece de trabalhar no coletivo. (PC6, em entrevista aos autores, outubro 2016).

Vê-se então que as próprias exigências do NEEF de se apropriar e criar com as TDIC foram muito importantes, destacando-se a percepção dos colegas de escola de que o aprendizado proporcionado pelo Núcleo aos professores participantes pode servir como catalisador de novas práticas com as TDIC em todos os componentes curriculares, tendo em vista a perspectiva da disseminação dos saberes por parte dos professores/cursistas na escola como um todo. De fato, um dos princípios da especialização era o "fortalecimento do coletivo no contexto escolar, agregando diferentes áreas e disciplinas a partir de um projeto comum para a escola" (RAMOS et al., 2013, p. 3), que acabou encontrando na experiência dos professores/cursistas o alicerce para se pensar articulações de integração das TDIC com os demais docentes das escolas.

Ao final, O professor/cursista 6 apresenta a percepção de que uma das maiores riquezas do Núcleo foi justamente apostar numa perspectiva de trabalho coletivo nas escolas, principalmente por levar em consideração que os representantes dos diferentes componentes curriculares acabam isolando-se no cotidiano pedagógico. Dessa forma, uma prática pedagógica alicerçada no diálogo entre os diferentes componentes curriculares representaria não somente um ganho em termos de construção de uma abordagem dos conhecimentos escolares, mas também o próprio fortalecimento dos coletivos escolares. 
Contribuições de um núcleo específico de educação física em um curso de educação... Juliano Silveira • Giovani De Lorenzi Pires

O professor/cursista 8, PC8, reafirma esse papel de uma formação que se estrutura a partir do coletivo escolar destacando que:

Tive várias intervenções dentro do núcleo, tanto na parte da educação física como nas outras áreas, quando eu ajudei também os outros professores. Então, são várias intervenções e isso me ajudou muito, abriu muito a minha cabeça para essas questões. (PC8, em entrevista aos autores, outubro 2016).

Assim, o docente entrevistado compreende que o fato de ter auxiliado no desenvolvimento das atividades dos colegas de grupo, durante os diferentes momentos do Núcleo, tenha sido um fator de extrema relevância para a sua formação, uma vez que envolveu reflexões sobre aspectos da prática pedagógica que até o momento desconhecia. É preciso considerar que um dos fatores para que os professores não utilizem as TDIC em suas aulas está ligado à falta de mediação de um parceiro mais experiente (BORTOLATO, 2016), com seus usos e possibilidades. Nesse caso, conforme demonstrado no depoimento do professor/cursista entrevistado, "o mediador pode ser um outro professor, da mesma disciplina ou de disciplina diferente, que aprendeu a lidar com as mídias digitais e se propõe a fazer junto com o colega, para que ele, mediado, possa elaborar sua própria prática pedagógica" (BORTOLATO, 2016, p. 33). Dessa maneira, mais uma vez a dimensão coletiva do processo formativo, que envolvia a interação entre diferentes componentes curriculares na construção de propostas de integração das TDIC nas escolas, tem seus méritos reconhecidos.

\section{Considerações finais}

Levando em conta a importância da abordagem da educação na cultura digital no âmbito da formação docente, sobretudo devido ao caráter recente de suas discussões e às demandas da educa- 
Contribuições de um núcleo específico de educação física em um curso de educação... Juliano Silveira • Giovani De Lorenzi Pires

ção contemporânea, tendem a ser louváveis os esforços em torno de uma avaliação de propostas formativas realizadas na presente perspectiva.

Dessa maneira, assumindo o compromisso de uma avaliação das repercussões das ações formativas do Núcleo Específico Educação Física e TDIC na prática pedagógica dos professores/ cursistas participantes, com base em suas percepções, foi possível realizar os seguintes apontamentos: os sujeitos entrevistados passaram a "aceitar melhor" as TDIC na escola; adquiriram maior segurança para propor ações com as TDIC em sala; perceberam a necessidade de se problematizar as tecnologias no cotidiano pedagógico em virtude das demandas educacionais contemporâneas, assim como a necessidade de se propor uma abordagem crítica e criativa com as TDIC nas aulas. Também revelaram ter uma melhor compreensão de como a Educação Física escolar pode apropriar-se das tecnologias propondo a própria ressignificação do trato com o conhecimento nesse componente curricular, além de enfatizarem a riqueza representada pelas possibilidades de trabalho coletivo nas escolas.

Face ao exposto, percebe-se que as temáticas abordadas ao longo do Núcleo Específico Educação Física e TDIC tiveram repercussões positivas sobre o cotidiano pedagógico dos professores/ cursistas, mostrando-lhes possibilidades de integração das tecnologias ao seu fazer pedagógico e também contribuindo para um processo de repensar a educação na contemporaneidade. Nessa perspectiva, as percepções dos sujeitos participantes da pesquisa, que culminou no presente artigo, tendem a encorajar o desenvolvimento de novas ações visando problematizar a educação contemporânea e contribuir para uma formação docente pautada nos princípios de uma educação na cultura digital.

\section{Referências}

ALMEIDA, M. E. B. Prefácio. In: COSTA, F. A. (Coord.) et al.

Repensar as TIC na educação. São Paulo: Santillana, 2012. p. 7-14. 
Contribuições de um núcleo específico de educação física em um curso de educação... Juliano Silveira • Giovani De Lorenzi Pires

BARDIN, L. Análise de conteúdo. $4^{a}$ Edição. Lisboa/Portugal: Edições 70 Lda, 2009.

BARTOLOMÉ, A. Comunicación y aprendizaje en la Sociedad del Conocimiento. Virtualidad, Educación y Ciencia - VEsC, Córdova, año 2, n. 2. ISSN: 1853-6530, p. 9-46, 2011. Disponível em: http:// revistas.unc.edu.ar/index.php/vesc/article/viewFile/332/331. Acesso em: 30 ago. 2015.

BELLONI, M. L.; BÉVORT, E. Mídia-educação: conceitos, história e perspectivas. In: Educação e Sociedade, Campinas, v. 30, n. 109, set./dez. 2009. p. 1081-1102. Disponível em: www.scielo.br/pdf/ es/v30n109/v30n109a08.pdf. Acesso em: 1 dez. 2016.

BIANCHI, P. Formação de professores e cultura digital: observando caminhos curriculares através da mídia-educação. 2014. 302 f. Tese (Doutorado em Educação Física) - Centro de Desportos, Universidade Federal de Santa Catarina, Florianópolis, 2014.

BORTOLATO, Márcia Melo. Inovação e práticas pedagógicas: o moodle no ensino presencial da Universidade Federal de Santa Catarina. 2016. 290 f. Tese (Doutorado em Educação) - Centro de Ciências da Educação, Universidade Federal de Santa Catarina, Florianópolis, 2016.

BUCKINGHAM, D. Precisamos realmente de educação para os meios? Comunicação e Educação. São Paulo, ano XVII, n. 2, jul/ dez 2012. p. 41-60. Disponível em: http://www.revistas.usp.br/ comueduc/article/view/73536/77235. Acesso em: nov. 2015.

BUCKINGHAM, D. Cultura digital, educação midiática e o lugar da escolarização. In: Educação e Realidade. Porto Alegre, v. 35, n. 3, p. 37-58, set/dez, 2010. Disponível em: seer.ufrgs.br/educacaoerealidade/article/viewFile/13077/10270. Acesso em: ago. 2015.

FREITAS, Maria Teresa de Assunção. A perspectiva sócio-histórica: uma visão humana da construção do conhecimento. In: FREITAS, M. T.; SOUZA, S. J.; KRAMER, S. (orgs.). Ciências humanas e pesquisa: leituras de Mikhail Bakhtin. São Paulo: Cortez, 2007. p. 26-38. 
Contribuições de um núcleo específico de educação física em um curso de educação... Juliano Silveira • Giovani De Lorenzi Pires

MINAYO, M.C. de S. O desafio da pesquisa social. In: MINAYO, M. C. de S. (org.). Pesquisa Social: teoria, método e criatividade. 31. ed. São Paulo: Vozes, 2012. p. 9-29.

PIRES, G de L. et al. Educação (Física) na cultura digital: memória da produção de um curso na modalidade EaD. In: CERNY, R. Z.; RAMOS, E. M. F.; BRICK, E. M.; OLIVEIRA, A. dos S.; SILVA, M. R. da. (org.). Formação de educadores na cultura digital: a construção coletiva de uma proposta. 1. ed. Florianópolis: UFSC/CED/ NUP, 2017, p. 125-155.

PIRES, G. De L.; LAZZAROTTI FILHO, A; LISBOA, M. M.; Educação Física, mídia e tecnologias: incursões, pesquisa e perspectivas. Kinesis, Santa Maria, v. 30, n. 1, p. 55-79, 2012. DOI: http://dx.doi. org/10.5902/010283085723

PRETTO, N. P.; ASSIS, A. Cultura digital e educação: redes já! In: PRETTO, N L.; SILVEIRA, S.A (org.). Além das redes de colaboração: internet, diversidade cultural e tecnologias do poder. Salvador: EDUFBA, 2008, p. 75-83.

QUARTIERO, E. M.; BONILLA, M. H. ; FANTIN, M. Políticas para la inclusión de las TIC en las escuelas públicas brasileñas: contexto y programas. Campus Virtuales, v. I, n. 1, p. 115-126, 2012, Revista Científica de Tecnología Educativa.

RAMOS, E. M. F. et al. Curso de especialização em educação na cultura digital: documento base. Brasília: Ministério da Educação, 2013. Disponível em: educacaonaculturadigital.mec. gov.br/downloads/documento-base.pdf. Acesso em: set. 2015.

RÜDIGER, F. As teorias da cibercultura: perspectivas, questões e autores. Porto Alegre: Sulina, 2011.

SILVEIRA, Juliano; BRÜGGEMANN, Ângelo Luiz; BIANCHI, Paula. Formação de professores de Educação Física e tecnologias digitais de informação e comunicação (TDIC)/mídia: uma relação possível? Análise das propostas curriculares de universidades federais brasileiras. Motrivivência, Florianópolis, v. 31, n. 57, p. 1-19, mar. 2019. DOI: https://doi.org/10.5007/2175-8042.2019e55308. ISSN 2175-8042. Disponível em: https://periodicos.ufsc.br/index. 
Contribuições de um núcleo específico de educação física em um curso de educação... Juliano Silveira • Giovani De Lorenzi Pires

php/motrivivencia/article/view/2175-8042.2019e55308/39009. Acesso em: 15 abr. 2020.

SILVEIRA, J.; PIRES, G. De L. Escola, docência, formação e mídia-educação (física): reflexões a partir da cultura digital. In: SHIGUNOV NETO, A.; FORTUNATO, A. (org.). 0 profissional de Educação Física e suas atividades: olhares multidisciplinares. São Paulo: Edições Hipótese, 2016. p. 91-109.

SOUZA NETO, A. Do aprender ao ensinar com as tecnologias digitais: mapeamentos dos usos feitos pelos professores. 2015. 398 f. Tese (Doutorado em Educação) - Faculdade de Educação, Universidade do Estado de Santa Catarina, 2015.

\section{Aprovação de comitê de ética em pesquisa}

Pesquisa aprovada pelo Comitê de Ética da Universidade Federal de Santa Catarina (UFSC). Número: 57911816.9.0000.0121

\section{Publisher}

Universidade Federal de Goiás. Faculdade de Educação Física e Dança. Publicação no Portal de Periódicos UFG. As ideias expressadas neste artigo são de responsabilidade de seus autores, não representando, necessariamente, a opinião dos editores ou da universidade. 